\title{
Resistências epistemológicas: entrevista com Dominique Tilkin Gallois ${ }^{1}$
}

\author{
Tatiane Maíra Klein² \\ Levi Marques Pereira ${ }^{3}$
}

DOI: http://dx.doi.org/10.20435/tellus.vi44.749

Tivemos o privilégio de trabalhar em alguns momentos de nossas vidas com Dominique Tilkin Gallois, professora colaboradora sênior da Universidade de São Paulo (USP) e pesquisadora do Centro de Estudos Ameríndios (CEstA). Nessas experiências de orientação à pesquisa e trabalho, ela nos beneficiou com sua generosidade e profundo conhecimento acerca dos modos indígenas de conhecer e metodologias de formação de pesquisadores indígenas, o que nos inspirou a realizar essa entrevista. Feita de maneira remota na manhã do dia 23 de junho de $2020^{4}$, a entrevista nos traz um pouco de sua história e de como se tornou pesquisadora em Etnologia e História indígena, abordando temas de grande relevância para as pesquisas realizadas com indígenas e por indígenas e contribuições importantes no campo teórico-metodológico e bem como nos processos políticos inevitavelmente envolvidos na pesquisa.

Como sua destacada atuação como antropóloga não se restringe aos temas acima, a conversa acabou sendo tangenciada por outros assuntos centrais em sua trajetória, como tradições orais e cosmologias ameríndias, políticas indígenas, patrimônio cultural e conhecimentos tradicionais. O modo sempre inovador como Dominique articula investimento acadêmico e ação indigenista também ganha

\footnotetext{
1 Nota de agradecimento: "Agradeço calorosamente Tatiane Klein e Levi Marques Pereira pela oportunidade de uma entrevista em que pude rememorar estadias inesquecíveis junto com Antonio Brand, no Mato Grosso do Sul. Nos últimos anos, devo a eles dois muitos aprendizados, através de suas belas pesquisas e de sua generosa dedicação aos Guarani e Kaiowa".

2 Universidade de São Paulo (USP), São Paulo, São Paulo, Brasil.

3 Universidade Federal da Grande Dourados (UFGD), Dourados, Mato Grosso do Sul, Brasil.

4 Em razão das restrições impostas pela pandemia de covid-19, a entrevista foi gravada por meio de uma plataforma de videoconferência online, sendo transcrita por Maria Carolina Botinhon Campos, cientista social, e posteriormente editada pelos autores.
} 
destaque através dos relatos de sua experiência na assessoria direta a comunidades indígenas no Amapá, norte do Pará e outros estados. Essas reflexões compartiIhadas nos permitiram uma aproximação com um certo fazer antropológico, que convidamos os leitores da revista a conhecer. Eis a "antropologia comprometida" de Dominique Tilkin Gallois.

Tatiane Klein: Gostaríamos que você começasse comentando uma afirmação de 2001, naquela entrevista para a equipe da Revista Sexta Feira. Ali você se identificava como tributária de uma "tradição muito antiga na Universidade de São Paulo (USP), de uma antropologia comprometida" (grifo nosso). Que tradição é essa e de que forma ela segue hoje?

Dominique Tilkin Gallois: Poderia recuar mais longe, mas a referência é o engajamento firme de Lux Vidal, minha orientadora. Essa tradição era reconhecida quando se falava dos "orientandos de Lux", e me orgulho que também seja lembrada com os "orientandos da Dominique". Lux, quando se tornou professora na USP, na época em que existia o Projeto Rondon, inseriu seus primeiros orientandos nesse projeto, mostrando como se pode articular pesquisa com intervenção: ajudar a resolver o problema da fome nos Krahô; enfrentar os conflitos em torno do castanhal dos Gavião, onde Lux introduziu lara Ferraz. Ela tinha experiência de trabalho no Pará, com os Xikrin. Os jovens antropólogos que ela orientava desenvolveram suas pesquisas não apenas a partir dos problemas percebidos em campo, mas buscando soluções. Pesquisa era isso: tem que entender o sistema de parentesco dos Krahô para entender esse problema da fome; e é assim que Maria Elisa [Ladeira] foi estudar parentesco. Por isso é que Lux foi tão corajosa, ao engajar jovens ainda inexperientes, em trabalhos tão complexos, e que deram resultados importantes. Tanto no mestrado como no doutorado, eu saía do processo de seleção com um projeto de pesquisa, ia para campo e voltava com outro, porque os índios me demandavam para entender alguma coisa que não era o que estava no projeto.

Essa antropologia comprometida é isso: fazer pesquisa em torno das demandas diretamente expressadas pelos índios. Quando comecei a orientar pesquisas, continuei o que eu aprendi com a Lux. No mestrado, eu trabalhava na Aliança Francesa para viver; num certo momento, fui demitida por justa causa, porque eu cheguei 15 dias atrasada, de volta dos Wajãpi. E Lux se preocupou: 
ela me apresentou para o Beto [Ricardo] e eu entrei no Centro Ecumênico de Documentação e Informação (CEDI). E aí meus colegas diziam: "Nossa, mas é gozado como a tua orientadora, ela está te ajudando a ser menos acadêmica [...]". Eu respondia: "Não. Um: ela está me ajudando porque eu preciso trabalhar; e dois: eu aprendo também fora da academia, aprendo muito lá no CEDI". E tenho certeza de que eu aprendi muito ao acompanhar dramas indígenas que pipocavam em todo o Brasil e que eram debatidos e monitorados no CEDI, e depois em outras Organizações Não Governamentais (ONGs) que se formaram na época. Da mesma forma, sempre insisti para meus orientandos se mexerem e os incentivei a atuar no indigenismo, porque isso ajuda a fazer uma boa pesquisa. Não é só um problema de conseguir apoio financeiro ao atuar nas ONGs: é que você tem de aprender a descrever questões complexas, que são ao mesmo tempo teóricas e muito pragmáticas. Então, você se aproxima das demandas indígenas e adquire a capacidade de mudar seu projeto, em atenção ao que estão esperando de você nas aldeias. A primeira coisa é isso: desmontar o projeto para atender o que eles querem. Enfim, eu acho que é simplesmente isso a antropologia comprometida. É uma antropologia que faz uma boa etnografia, justamente porque é preciso atender problemáticas diretamente colocadas pelas comunidades. Ainda bem que tem alunos que ainda desejam fazer uma antropologia muito atenta às questões locais, aceitam modificar seus projetos, mesmo se acabam por dar menos atenção às teorias da moda e mais, vamos dizer, ao que importa, realmente, para os índios. Eu acho que é isso, porque o viés antropológico sólido - a boa formação acadêmica - se potencializa no campo indigenista e permite que você trate essas questões com profundidade. Mas precisa de tempo. Hoje, sem financiamentos para formação mais vagarosa e pesquisa de campo prolongada, a coisa está ficando muito difícil. Muito difícil. Eu sempre mantive, articulados, um investimento na academia e um investimento no indigenismo. Entrei na USP graças à Manuela [Carneiro da Cunha], que me inscreveu num concurso enquanto eu estava nos Wajãpi, sem comunicação. Quando voltei, pensei: "É... por que não?”. Aí fui e passei [no concurso]. Pouco depois, ela fundou o Núcleo de História Indígena e do Indigenismo (NHII) e [ali] eu construí meu primeiro projeto temático, sobre [redes de] relações nas Guianas 5 .

5 Projeto temático "Sociedades indígenas e suas fronteiras na região sudeste das Guianas", desenvolvido entre os anos de 1995 e 2003, com financiamento da Fundação de Amparo à Pesquisa 
A criação do CEstA, que substituiu o NHII, foi importante também, porque pacificou certas relações. Na composição dos centros de pesquisa no Brasil, vocês sabem, tem alguns antropólogos que aderiam tanto ao viés estruturalista que achavam que um investimento em problemáticas da história e do indigenismo eram coisa do passado, menos glamorosas. O CEstA se abriu para problemáticas transversais, bem diversificadas, diluindo as dissensões, tanto com relação ao viés da história indígena - que sempre defendi no NHII e foi muito importante para mim - , quanto em relação à educação escolar indígena, que era um viés da Aracy [Lopes da Silva] e do MARI (Grupo de Educação Indígena da USP), que ela criou e foi incorporado no NHII.

Levi Marques Pereira: Quais foram as inovações desta abordagem das "redes de relações" para a Etnologia indígena?

Dominique Tilkin Gallois: Nossos resultados foram muito interessantes, porque construídos por uma equipe que apostou radicalmente na comparação regional e na colaboração densa entre todos, como se vê na publicação final. Mas esses resultados sofreram uma crítica virulenta de pessoas ligadas ao Peter Rivière que, vamos dizer, era o dono da sabedoria sobre as Guianas - e isso foi bastante desanimador. De uma certa maneira, porque nós tínhamos mostrado que ele tinha elevado a um parâmetro estrutural a descrição de um modo de relação que era puramente contingencial, devido a um certo momento histórico no qual ele tinha analisado os Trio no Suriname. E ele continuava dizendo que esses povos eram formados por grupos fechados sobre si. Nós queríamos mostrar que isso era absolutamente circunstancial e fizemos a prova da extensão das relações, atestadas não só pelas extensas redes de troca, como pelo multilinguismo etc. Mas aí apanhamos bastante, e a discussão ficou por isso mesmo. Eu fui me interessar por outras questões, que despontavam já há tempos nas minhas experiências em campo, relacionadas às práticas de conhecimento e aos modos de saber. Questões que só podem ser analisadas corretamente levando em consideração conexões múltiplas, no contexto de densas redes de relações. Por isso, os resultados dessas pesquisas em torno das redes são inovadores com certeza, e uma das coisas mais

do Estado de São Paulo (Fapesp), processo n. 95/00602-0. Seus resultados foram apresentados no livro "Redes de relações nas Guianas" (GALLOIS, 2005). 
animadoras, que aconteceu nos últimos 10, 15 anos, é que muitos arqueólogos que trabalham na região das Guianas estão se apoiando firmemente nessas abordagens das redes, porque é a única maneira através da qual eles conseguem explicar a composição de sítios, nos quais há evidência de trocas de todo gênero - que antes eram abordadas como mudanças históricas. O foco nas unidades sociais, nas fronteiras étnicas, nas chamadas "tradições arqueológicas", impedia ver a densidade das trocas atestadas pela diversidade de vestígios encontrados num sítio.

Então, apostar radicalmente no estudo das redes nas Guianas foi muito legal para nós: Denise Fajardo, Renato Sztutman, Gabriel Barbosa, Carlos Dias, Nadja Havt, Antonella Tassinari, Juliana Rosalen, Rogério do Páteo e claro, Lux, para citar alguns membros daquele primeiro projeto. Mas as inovações carregadas por esta abordagem não vingam em toda parte; ainda é preciso combater visões centradas no isolamento, na suposta particularidade do "étnico", como fazem certas antropologias ligadas ao indigenismo, especialmente na Fundação Nacional do Índio (Funai). É um viés característico de quem afirma, por exemplo: "Ah! Os Zo'é têm uma cultura que é só deles. Olha esse brinco zo'é! Esse colar zo'é! Único!". Não são únicos, coisa nenhuma! São os mesmos que os povos vizinhos usam: são tecnologias, formas e significados que resultam de intensas trocas. Os Zo'é que foram tidos como isolados durante muitos anos, nos trazem inúmeras evidências em sua cultura material da intensidade desses encontros, histórias de relações antiquíssimas, com povos vizinhos karib. Se você vai verificar na língua, tem palavras karib na língua zo'é e palavras zo'é nas línguas karib. Então, essa abordagem que deixa de focar apenas unicidades, unidades fechadas, buscando entender fluxos e redes, para mim é essencial. E isso, sobretudo, monstra que não se pode descrever relações sociais ou sistemas de conhecimento a partir de um interior e um exterior. Um dos exercícios realizados na pesquisa temática das Guianas, que julgo bem-sucedido, foi mostrar que não dá para dizer que há diferenças entre "trocas internas" e "trocas externas", como seria o procedimento de trocas na cantina da Funai. São contextos que devem ser abordadas a partir de um mesmo esquema de relações, como fez Gabriel [Barbosa], que mostra como os modos de operar trocas supostamente "internas" ou "tradicionais" também sustentam os procedimentos de venda de artesanato na cidade (BARBOSA, 2007). 
Eu tenho em mente a frase de um velho wajãpi, o chefe Waiwai, que foi determinante para que eu entendesse isso, há 30, 40 anos. Um dia, fui com ele para a cidade de Macapá e a gente pegou a estrada Perimetral Norte. Chegando na cidade, ele me disse: "Esse é realmente o meu caminho, erape". Esse percurso se estende inclusive dentro de Macapá, conecta a cidade com sua aldeia, distante no extremo norte da Terra Indígena (TI), faz parte da vida dele. Estar atento a esse tipo de conexões foi um ensinamento ao qual me dediquei muito na orientação dos meus estudantes. Eu não gosto muito dessa coisa: "Ah, então vamos estudar os índios na cidade". [...] Separando o que nossos interlocutores não separam. Não. É estudar as intrincadas conexões que eles fazem entre pessoas, grupos, tipos de gente, entre cidade e aldeias. Isso é uma coisa contra a qual eu venho lutando há muito tempo. É muito difícil romper com a tendência em separar dentro e fora. A sensação que eu tinha de muitos colegas pesquisadores, quando comecei a fazer Antropologia, nos anos 1970 e 1980, era [a de que] eles se enfiavam em uma Terra Indígena e aí estudavam "os" Mebêngôkre, "os" não sei quem, "os" não sei o quê... Como se esses povos estivessem contidos dentro dessas unidades, como "etnia" ou "terra indígena". Obviamente não. A gente tem que seguir os caminhos, os fluxos que entram e saem, que conectam várias unidades, espaços e tempos.

Tatiane Maíra Klein: A partir daí, como se deu teu interesse pelo tema dos modos de saber, das práticas de conhecimento indígenas?

Dominique Tilkin Gallois: Deriva do meu investimento em entender o que se passava nas escolas indígenas, aliás um interesse que nasceu de uma demanda expressa dos Wajãpi no início dos anos 1990, quando a professora da Funai foi substituída pelas funcionárias ambíguas e ausentes da Secretaria de Educação do Estado. Comecei a ver isso na escola deles e também nas salas de aula nas aldeias dos Karipuna, Galibi e Palikur no baixo Oiapoque. Eu era muito amiga do Padre Nello [Ruffaldi] - que faleceu no começo do ano [de 2020], infelizmente -, do CIMI (Conselho Indigenista Missionário). Fui assessora do CIMI durante um tempo, então, dentro de minhas atividades no CEDI, fazia formação do pessoal do CIMI para trabalhar em escolas indígenas. E estava apavorada em ver a maneira absolutamente antiquada como era abordada a escola. Quer dizer, mesmo os melhores e bem-intencionados missionários do CIMI continuavam vendo os alunos indígenas como páginas em branco; não conseguiam dar espaço aos saberes locais, 
pois não concebiam e, portanto, não consideravam a possibilidade de existência de práticas de conhecimento que não fossem escolares. Então, bem mais tarde, com as escolas adentrado pesadamente na vida dos índios, isso me levou a esse outro foco de interesses e de pesquisas.

Com o CIMI eu não briguei, mas com a Secretaria de Educação do Amapá, no caso Wajãpi [Amapá], foram brigas enormes! Enquanto isso, meus alunos - como Flora [Dias Cabalzar], que trabalhava com os Tuyuka [Amazonas] e agora com os Zo'é - tinham embates com outras secretarias. Quer dizer: nós começamos a ter brigas com secretarias de educação; todos nós! E é muito importante lembrar que as universidades e as ONGs haviam sido convidadas a implantar projetos-piloto de formação de professores indígenas e de Projetos Político-Pedagógicos (PPPs) que, depois, as secretarias deveriam assumir, tomar para si, atualizar e ampliar. Mas não. Expulsaram simplesmente os "não-governamentais" e os pesquisadores de universidades que atuavam na educação escolar indígena ${ }^{6}$. Estou pensando no caso da Jussara Gruber, nos Ticuna [Amazonas]: quando ela começou a formação dos professores. Foi afastada; a secretaria tomou conta e negou todo o aporte e o conhecimento sofisticado acumulado por Jussara e sua equipe. Nós enfrentamos isso no Brasil em todos os lugares. Então, os antropólogos fizeram trabalhos muito legais na tentativa de construir escolas diferentes... e depois voltou-se a uma escola não diferenciada, muitas vezes não apenas aceita mas cobrada pelos índios; e tivemos de recomeçar o trabalho todo. O Levi sabe disso, porque acho que recomeça a ser interessante, quando os indígenas chegam na universidade.

Levi Marques Pereira: Falando nisso, como foi sua aproximação com o Mato Grosso do Sul e a formação dos pesquisadores indígenas ligados ao Programa Redes de Saberes, do Núcleo de Estudos e Pesquisas das Populações da Universidade Católica Dom Bosco? (NEPPI/UCDB)

Dominique Tilkin Gallois: Eu não me lembro como Antonio Brand me achou. Fui em um daqueles seminários anuais ${ }^{7}$, há muito tempo, em que participei e falei algumas coisas. Aí o Antonio me disse: "Nossa, legal. Você vem dar aulas para

${ }^{6}$ Experiências construídas e destruídas bem analisadas na tese de Luis Donisete Grupioni (2008).

7 Seminário Povos Indígenas e Sustentabilidade, realizado pelo Programa de Pós-Graduação Stricto Sensu em Educação (PPGE) da UCDB, pelo NEPP e pelo programa Rede de Saberes. 
nossos alunos?". Então eu fui dar um curso sobre sistemas de conhecimento, sobre procedimentos de sistematização do conhecimento tradicional. Antonio me mostrava os programas das disciplinas e fiquei estarrecida, pois nessa formação não havia espaço para que os alunos indígenas falassem de seus saberes, em moldes próprios. A ideia era que deveriam primeiro ler os antropólogos e a partir deles descrever aspectos da cultura de suas comunidades. Daí, nos cursos que organizei, consegui fazer a prova para Antonio de que os alunos indígenas tinham condições de falar deles e de seus saberes, sem antes terem lido os antropólogos. Essa era a minha briga, porque a primeira coisa que o Brand queria fazer na formação dos professores indígenas era criar condições pedagógicas para que eles conseguissem estudar uma quantidade enorme de obras clássicas - aliás, uma literatura bem velha, pois a etnologia regional ainda não estava tão renovada como está hoje. Liam-se trabalhos culturalistas ou funcionalistas sobre Guarani, Bororo, Terena... E eu falava: "Não, não, não! Você tira tudo isso e você começa a formá-los, dando a palavra para eles, para eles começarem a refletir sobre si mesmos, sem enviesar a descrição da própria cultura a partir das análises dessa antropologia envelhecida". Isso se reforçou, porque eu comecei a fazer parte de bancas de defesa e a criticar a ausência de análises mais originais e autônomas nos trabalhos dos chamados "acadêmicos indígenas".

Me lembro de um mestrado sobre território terena, no qual a dissertação começava com a definição copiada de um dicionário e, depois, seguia com algumas definições de território pelos antropólogos e, depois, não sei quê [...]. Eu falei: "Não quero saber disso. Me diz você: o que é território para você, para teus familiares?". Esse caso foi muito interessante, porque eu mostrei para o Antonio: "Não dá. Ele não consegue mais refletir a partir dos saberes locais. Ele está completamente enviesado pelas definições livrescas". E foi ali que ele me convidou para participar de mais cursos na UCDB [Universidade Católica Dom Bosco]. Acho que eu fui umas três vezes; ficava uma semana e alternava os cursos com a Marta Azevedo.

Naquela época, eu estava começando a formação de pesquisadores nos Wajãpi, e Antonio ficou interessado e então eu fui fazer essa oficina lá em Caarapó. Foi muito legal e, de novo: sem material prévio. Ele dizia: "Você não tem apostila? Você não tem programa [...]"; e eu falava: "Não. Não tem que ter apostila nenhuma. Você junta as pessoas e puxa um assunto e são eles que vão sistematizar". A 
apostila vai sair da reflexão deles. Na verdade, esse era meu método. Quer dizer: como ajudar os próprios professores ou pesquisadores indígenas a eles mesmos encontrarem o caminho da sistematização, sem caixinhas prontas. Era isso. Foi determinante: fui para Caarapó com dois Wajãpi. Eu queria ter ido mais vezes. Foi muito importante para mim essa colaboração com pesquisadores como Antonio, no Mato Grosso [do Sul].

Eu me lembro da primeira vez que eu entrei, andei ali [na aldeia Te'ýikue]... Se eu fechava os olhos e só escutava, eu estava em uma aldeia wajãpi! Quer dizer: até o pátio da casa, as plantinhas no pátio, a casa com seus puxados, e a língua eram muito parecidos. Tirando o fato [de] que em Caarapó, estava escancarado o confinamento territorial: olhando de um lado, você via o boi, do outro você via a soja. Mas era emocionante para mim perceber o quanto o modo de organização das relações familiares era próximo dos tupi da Amazônia. Muito, muito, muito mesmo!

[Essa colaboração] foi essencial para mim, para entender o quanto a formação pode enviesar os pesquisadores indígenas e dificultar o trabalho deles a encontrarem seus próprios modos analíticos. Quando eles absorvem conceitos, categorias descritivas sem antes buscar evidenciar seus próprios conceitos, seus próprios modos de comparar etc. Então eu queria que, antes de estudar os etnólogos, eles pensassem por eles mesmos. E eu sei que em muitos lugares você continua tendo formações que vão deformando os pesquisadores. Em Caarapó, no primeiro dia, todo mundo me falou da identidade; aí no segundo dia não aguentei e falei: "Vamos ter uma conversa? Vocês não vão usar nem a palavra identidade, nem a palavra cultura. A gente vai trabalhar de modo diferente e vocês vão me explicar as coisas com suas próprias palavras, sem usar esses termos identidade e cultura". Foi difícil, mas acho que cutucou, entendeu? Foi uma certa alegria, quando eles perceberem que podiam falar de seus conhecimentos e práticas atendo-se a coisas pragmáticas: os saberes são práticas e são essas práticas que têm de descrever, evidenciar, para então seguir buscando os conceitos próprios. Isso é o que eu queria.

Levi Marques Pereira: Eu assisti a muitas aulas do Antonio Brand na Licenciatura Intercultural Indígena Teko Arandu, - e, a partir dessa oficina que você fez em Caarapó, ele adotou isso como metodologia nas aulas.

Dominique Tilkin Gallois: Ah! 
Levi marques pereira: é! Tanto nas aulas que ele dava no Teko, quanto no Ára Verá, que é o Ensino Médio, como também nas oficinas na Secretaria Especial de Saúde Indígena (SESAI), para agentes de saúde - formações que era requisitado para fazer-, ele sempre partia dessa metodologia. E eu achava muito interessante, mas não sabia a origem. Agora que eu soube.

Dominique Tilkin Gallois: É isso, é isso! É muito mais difícil fazer isso no Mato Grosso do Sul - como é mais difícil fazer nas aldeias do baixo Oiapoque, onde os indígenas têm uma escolarização antiga e, portanto, pesadamente deformadora - do que fazer com os Wajãpi, onde a escola simplesmente não funcionava e portanto não deixava rastros. Você entende o que eu quero dizer? Então, eles ainda não estavam confundidos pelo linguajar escolar... Mas é isso, tem outros riscos. Uma vez um pesquisador wajãpi me disse: "Você é culpada! Você não é uma boa antropóloga". Eu falei: "Por quê? O que aconteceu?"; "Não, porque a professora falou que você não ensinou o que é identidade para a gente". Vocês entendem? Então eu tive que correr atrás de [explicar o] porquê: porque aí a palavra identidade matava a charada de tudo e não se sabia nada de novo. Eles não conseguiam dizer nada além de "minha identidade". Nada mais. Nada. As práticas deles sumiam embaixo dessa categoria ambígua e vazia de sentidos locais.

Tatiane Maíra Klein: Essa metodologia surge, então, do teu trabalho com as escolas?

Dominique Tilkin Gallois: Vai mais da minha observação da escola. Antes de meter a mão na massa e aprender a construir PPP, materiais didáticos etc., tive a oportunidade de observar o que se fazia nessas escolas. Vem mais dali, do pavor de ver como não só não se dava espaço aos saberes indígenas na escola, como se impedia o surgimento de alternativas na descrição e análise de práticas sociais e saberes associados. Porque o que está claro para mim - decorrente dos resultados de "redes de relações nas Guianas", mas sobretudo de "redes ameríndias" 8 -, é que a gente tem que atentar para os modelos analíticos em vigor nessas comunidades, modelos que estão sempre em transformação. Eles

8 Projeto Temático "Redes ameríndias: geração e transformação de relações nas terras baixas sul-americanas", desenvolvido entre os anos de 2007 e 2012, com financiamento da Fundação de Amparo à Pesquisa do Estado de São Paulo (Fapesp), processo n. 05/57134-2. 
têm modos de descrever as relações sociais, que são analíticos também, porque se você descreve de um jeito, é porque você o analisa desse jeito. Meus orientandos - a Joana [Cabral], a Eva Gutjahr, o Igor [Scaramuzzi], vários - foram trabalhar na formação de pesquisadores Wajãpi e aí a gente fez coisas maravilhosas, que duraram um certo tempo. Mas depois os padrões convencionais das Secretarias foram impostos novamente nas escolas dos Wajãpi. Então, a guerra continua, de uma certa maneira. E aí, a solução foi aderir ao Programa Saberes Indígenas na Escola, do Ministério da Educação (MEC), através do qual eu consegui recuperar, um pouco, algumas atividades junto aos professores Wajãpi, incentivando-os a repensar o que eles querem ensinar em suas escolas.

Acho que o que está acontecendo com a pandemia agora, para mim, é uma medida de sucesso do nosso trabalho. Os Wajãpi sumiram do mapa. Eles captaram imediatamente os desafios e a grande maioria deles não foram buscar os $\mathrm{R} \$ 600$ reais (BARBOSA, 2020) ${ }^{9}$ na cidade: se isolaram. Escrevem diários da pandemia, têm uma produção; conseguiram placas solares para fazer funcionar a internet em suas casas; botaram os velhos em aldeias distantes de cinco dias a pé do posto [...] estão cuidando de suas vidas, enquanto outras comunidades, que não tiveram uma formação reflexiva sobre o teor das relações com os não-índios, ficaram lá nos postos, aguardando a máscara, a cesta básica, esperando os brancos ajudarem e se contaminando. Está uma tragédia entre tantos povos que não se isolaram. Então, posso dizer que o trabalho indigenista que procuro realizar consiste em incentivar sempre meus interlocutores a uma reflexão crítica sobre "Quem somos nós?", "O valor dos nossos conhecimentos". Alguns me mandam notícias: "Ah, sa'i [...]" - vovó, como eles me chamam - "minha família retomou o arco e flecha para caçar, porque acabou a munição lá"; "Nós estamos muito bem, comendo muito peixe". Quer dizer: eles recorreram às práticas de subsistência que ainda estão muito vivas - apesar de estarem sempre experimentando outros modos de viver -, e foi isso que possibilitou o refluxo para o isolamento. Estão fazendo festas, com muito caxiri. Aí, eu acho que os

9 Faz referência ao Auxílio Emergencial, benefício financeiro no valor de $\mathrm{R} \$ \mathbf{6} 60$ instituído pelo Governo Federal em março de 2020, para o período de enfrentamento à pandemia de covid-19. Segundo reportagem de Catarina Barbosa (2020), publicada pelo jornal Brasil de Fato em maio de 2020, o deslocamento de indígenas para receber o benefício no valor de $\mathrm{R} \$ 600,00$ nas cidades foi responsável por expor aldeias inteiras ao novo coronavírus. 
evangélicos que tentam converter os Wajãpi perderam um pouco o pé, porque não conseguiram mais fazer os cultos.

Na verdade, o que eu quero dizer com isso é que tem que ser um pouco radical. A formação de pesquisadores tinha um foco político muito evidente, que era o de incentiva-los de várias maneiras a refletir sobre a capacidade de vida sustentável que os saberes indígenas promovem. E um caso de pandemia é exatamente isso: "de repente a gente pode viver sem as coisas dos brancos"! Mas, para isso, teve que ter uma reflexão sobre práticas, conhecimentos. E não é fácil. Os jovens wajãpi que não participavam da formação dos pesquisadores, durante os 15 anos que durou oficialmente o plano de salvaguarda ${ }^{10}$, criticavam a turma em formação, porque eles tinham que trabalhar na roça e diziam: "Ah, você vai ficar para a roça! Eu não: eu vou ganhar dinheiro na cidade". Então, havia esse embate. Estudar fora, não estudar fora. E agora, com a pandemia, o valor das práticas de vida se mostrou essencial e os $\mathrm{R} \$ 600$ foram os "R\$600 reais da morte". Os indígenas do Oiapoque, apesar de algumas lideranças terem tentado impedir a saída em massa para a cidade para pegar benefícios, voltaram da cidade e 15 dias depois foram infectados de uma maneira radical. E o número de mortes vai continuar ocorrendo, assustadoramente, pela própria dificuldade de viver sem os apoios de fora.

É um pouco delicado falar dessas coisas, porque há populações indígenas que não conseguem mais viver de outro jeito, pois vivem em terras arrasadas e precisam mesmo da cesta básica. Mas é grave quando você tem populações como os Wajãpi - e quem diria, os Zo'é -, que não precisam porque têm roças fartas, caça e peixe em seu território, e são quase obrigados a precisar da cesta básica. O Programa Wajãpi do lepé (Instituto de Pesquisa e Formação Indígena) está lutando para impedir as agências oficiais de promover agrupamentos do tipo: "Ah! Nós vamos entregar cesta básica, mas um chefe de família tem que vir buscar". Aí pronto [...] porque [a Terra Indígena] Wajãpi não tem estrada, são caminhos a pé. Então buscar e levar a cesta básica, cinco dias a pé, para chegar em uma aldeia remota e levar o coronavírus?

\footnotetext{
${ }^{10}$ Plano de Salvaguarda do Patrimônio Imaterial Wajãpi, elaborado e implementado após o registro das "Arte Kusiwa: expressões gráficas e orais dos Wajãpi" como bem cultural pelo Instituto do Patrimônio Histórico e Artístico Nacional (IPHAN), em 2002, e seu reconhecimento em 2003 como Patrimônio Cultural Imaterial da Humanidade, pela Organização das Nações Unidas para a Educação, a Ciência e a Cultura (UNESCO).
} 
Nós estamos falando, na verdade, de lutas sobre modos de vida e dependência. Esse era o foco do meu trabalho na formação de pesquisadores: uma valorização eficaz dos conhecimentos pragmáticos deles para manter a qualidade de vida. Não era só faze-los falar de xamanismo, cosmologia... também, mas, sobretudo, de aguçar sua percepção da qualidade de seu modo de vida. As pesquisas eram sobre isso: conhecimentos da roça, venenos de pesca, remédios do mato, essas coisas. Saberes pragmáticos, que agora estão sendo usados. Enfim: não precisam fazer ensaios filosóficos. Isso, quando se chega à universidade, muda um pouco. Mas, no caso dos Wajãpi, era uma formação não universitária, uma formação de pesquisadores que vivem em suas aldeias remotas e que não foram para a universidade. Então, é muito especial. Na universidade é diferente.

\section{OS PERIGOS DA INTERCULTURALIDADE}

Levi Marques Pereira: Como você avalia o interesse e a apropriação da educação escolar pelos indígenas no período pós-Constituição de 1988? A emergência do paradigma da educação intercultural garantiu espaço aos saberes indígenas?

Dominique Tilkin Gallois: Naquele texto que vai ser publicado no livro do I Seminário Internacional de Etnologia Guarani: diálogos e contribuições ${ }^{11}$ desenvolvi algumas questões [referentes a esse tema]. Primeiro: interculturalidade nunca foi o meu parâmetro nas formações que eu coordenei e nos cursos que ofereci. Acho que antes de chegar à interculturalidade - que insiste numa certa "mescla", "inter" - a gente tem que confrontar. Então, esse é meu método: o de comparar contrapondo. Porque o uso acelerado ou, vamos dizer, descuidado da ideia de interculturalidade parece que elimina os efeitos do campo do poder. Então, interculturalidade, no limite, é que nós, de um lado ou de outro, temos uma influência mútua, certo? "Inter" é isso. Só que, muitas vezes, o intercultural é pensado como um "falar da cultura de um grupo nos moldes de outro grupo", que é o grupo dominante.

Eu dou exemplo de um dos primeiros professores wajãpi a ingressar numa formação universitária, que estava todo feliz, porque tinha estudado as formas

\footnotetext{
${ }^{11}$ Lauriene Seraguza Olegário e Souza e Levi Marques Pereira (organizadores). Editora da Universidade Federal da Grande Dourados (UFGD), no prelo.
} 
geométricas da Matemática - triângulo, losango... - e, em vez de usar as categorias descritivas próprias da pintura corporal, que constituem um modelo analítico regional muito interessante, evidenciando a forma como são percebidos os desenhos - borboleta, pernas de rã e assim por diante -, ele começa a descrever os grafismos a partir da nomenclatura da geometria ocidental. Aí se perde a nomenclatura indígena. Por isso é que eu acho que, no começo da formação de professores indígenas e também na universidade, o mais importante é perceber as diferenças. Antes de procurar soluções da mediação - que é quando se corre o risco de os modelos analíticos e descritivos ensinados na escola se sobreporem aos modelos indígenas -, a gente tem que comparar contrapondo.

Outro exemplo da experiência de formação de professores wajãpi na licenciatura intercultural. No começo dessa formação - agora mudou, e está bem mais interessante - ao invés de pedir para ele como é que os Wajãpi pensam e como eles fariam a descrição de seus artefatos, enfiaram o dicionário de cultura material de Berta Ribeiro. Então, ele faz um trabalho sobre os bancos wajãpi e só diz que os bancos são monóxilos, entalhados em uma madeira dura etc. E esquece de dizer as coisas mais relevantes sobre esses bancos, por exemplo, que, à noite, o banco tem que ser colocado em pé, senão os espíritos dos mortos vão vir sentar no banco e infernizar a vida dos vivos; que determinadas pessoas podem ou não podem sentar no banco de outra pessoa.

Então, na verdade, o intercultural é, muitas vezes, a mesma coisa que formatar as descrições culturais indígenas nos moldes das tradições ocidentais. Para mim, tratar de interculturalidade não é o foco importante na formação inicial de pesquisadores indígenas. Acho que a linguagem do intercultural, um dia pode ser retomada, quando os modelos descritivos e analíticos indígenas - do grupo em formação - tiverem sido sistematizados de forma suficientemente poderosa para influenciar os nossos modelos. Isso acontece de fato através de trabalhos antropológicos; o perspectivismo, por exemplo, é um modo analítico indígena que vem para a Antropologia ${ }^{12}$. Mas geralmente na escola [indígena] não chega a ser dessa forma. Então esse intercultural não é efetivo. Eu me lembro, por exemplo,

\footnotetext{
12 Dominique refere-se ao fato do conceito de perspectivismo ameríndio ter sido formulado por Tânia Stolze Lima (1996) e Eduardo Viveiros de Castro (1996) a partir de um modelo analítico compartilhado por diversos povos ameríndios, identificado em trabalhos etnográficos anteriores.
} 
no caso dos Yanomami, tinha uma coisa que sempre me deixou impressionada. Eles chamavam de "matemática indígena" a adoção do sistema decimal com, simplesmente, palavras em yanomami para descrever esse sistema de numeramento. Mas o decimal não é o modo como os Yanomami comparam quantidades e volumes. Qual é esse modo? Vamos botar ele na escola também, por favor? Esse é o meu problema com o intercultural: ele supõe um equilíbrio que não há, se a gente não percebe a dominação epistemológica que acontece nas escolas. Então precisa ser muito bem preparado para realizar uma formação ou um material didático intercultural. Então, primeiro, por que não confrontar?

Também tem aquela coisa das disciplinas: quem disse que existe no pensamento indígena uma Geografia separada da História? Para mim isso é absurdo. Uma das minhas principais brigas com a Secretaria [de Educação] do Amapá é que, na formação de professores, todas as matérias que eu tinha dado de História e Geografia enquanto uma única disciplina foram invalidadas, porque deveria ter oferecido os conteúdos em disciplinas separadas. Então, esse formalismo das caixinhas impede o surgimento de outras maneiras de pensar sobre as relações entre tempo e o espaço. Valorizar os chamados conhecimentos indígenas "tradicionais" é, primeiro dar chance para que eles tenham um espaço para serem sistematizados, a partir dos modelos indígenas, e não a partir da importação de modelos analíticos ocidentais. Tenho muitos exemplos disso. "Seres vivos" e "seres inanimados"... isso para mim é o pior de tudo! Isso é uma concepção ocidental, de que existe essa distinção entre seres vivos e seres inanimados na cultura karajá. Será? Ou será que sabemos que, para os ameríndios, essa distinção não procede? Então, por que ela é transportada? E isso é chamado de intercultural, vem no título do material didático. Não; isso é a dominação da nossa epistemologia sobre os saberes indígenas. Eles têm um caminho difícil a traçar ali, e isso depende, agora, dos acadêmicos indígenas.

Levi Marques Pereira: Essa abordagem que você propõe está muito centrada na distinção entre os sistemas epistemológicos: a epistemologia indígena e a científica, vamos dizer assim...

Dominique Tilkin Gallois: Científica, não. Nas escolas indígenas ela não chega. Nem chega em muitas licenciaturas ditas interculturais. Eu sempre distingo, quando eu dou essas formações: científico é uma coisa; nas escolas você não tem o 
científico, tem o escolar. E o escolar é um reduzido do científico, empobrecido, sem o teor questionador do científico. No científico você tem o perspectivismo, por exemplo, que não chega no escolar. É por isso que eu aposto na presença indígena nas universidades, porque lá eles vão se encontrar com o científico e não apenas com o escolar. Não é a mesma coisa. Então eu aposto na capacidade da formação dos pesquisadores indígenas em perceber a radical diferença entre modos de conhecer, entre vários sistemas ou regimes de conhecimento indígena a serem contrapostos com regimes de conhecimento científico. O problema é reduzir o científico ao escolar.

Quando você fala "Geografia Indígena", por que é que tem que ser "Indígena"? Por que a Geografia seria separada de outra coisa? O que é "Geografia Indígena"? Eles têm que absorver o recorte disciplinar escolar ocidental e enfiar coisas dentro e tirar outras? Na verdade, isso não questiona a separação em disciplinas? Não questiona [...] Então, para mim o importante é, sobretudo, apoiar os pesquisadores indígenas a romper as caixinhas. Isso são as matérias com as quais eu trabalho na prática com os pesquisadores wajãpi. Como é que você vai descrever um animal ou um bicho qualquer? Descrevendo onde ele mora, a planta que ele come, mostrando como todos os elementos de uma descrição feita por eles estão totalmente articulados. Então eles perceberam que nenhum saber se encaixa integralmente dentro de uma caixinha. E o saber escolar os obriga a separar: separar o mito da história; Zoologia separada de Botânica... e percebem que o modo de aprender na escola gera muitos problemas, não encaixa com seus modos de dizer, de ensinar.

Tatiane Maíra Klein: Qual seria uma boa forma de romper com as caixinhas nas formações de pesquisadores indígenas nas universidades?

Dominique Tilkin Gallois: Eu continuaria recomendando, uma etnologia mais clássica, de saber como e o que se diz, como se fazem as coisas ali de maneira etnográfica, próxima. Para mim, tudo que incentiva a se distanciar do fazer etnográfico, de uma formação que atenta aos modos de pensar, de fazer, de conhecer - que exige um conhecimento denso dos contextos locais e claro, da língua etc. -, não é algo que me atrai. É isso. E o que me assusta é que, por vezes, os indígenas que vão para a universidade se embrenham em pesquisas ditas "descoloniais", grandiosas, distantes do pátio das aldeias, quando eles justamente teriam a chance de 
poder refletir sobre saberes locais. Então, há uma certa tensão entre antropólogo que aposta no pós-colonial, descolonial, e aqueles que continuam, muito classicamente, procurando entender o que se passa no miúdo do cotidiano. É claro que o local é influenciado pelo global, mas bem, justamente por esse motivo, vamos etnografar! Quanto mais a gente continuar se maravilhando, descrevendo bem como se sabe alguma coisa, como se conhece a si e ao outro, como se descreve uma relação social, as conexões entre pessoas e coisas, melhor a gente vai poder ajudá-los a valorizar esses saberes. Só dizer: "Ah, os saberes são colonizados...", eu acho que é pouco.

Levi Marques Pereira: Lembra um pouco o que o [Marshall] Sahlins (1988) já dizia: que o ponto de vista local, ele também é global [...]

Dominique Tilkin Gallois: Exatamente. Necessariamente. É por isso que foram tão importantes os resultados em "Redes de relações nas Guianas", porque as pesquisas articularam relações que se constroem a partir dessa articulação. Estou pensando agora nos Waiwai e no Carlos [Dias Júnior], meu aluno. Ele estudou as conferências evangélicas dos Waiwai para mostrar como funcionava o sistema político deles (DIAS JUNIOR, 2005). As coisas estão ali: na conferência evangélica você tem a organização social waiwai potencializada. São essas coisas, mas se ele não conhece bem como funciona lá, localmente, ele não vai dar conta da articulação disso.

Tatiane Maíra Klein: Lembrei, enquanto você falava do Brand, de uma formação pedagógica em que eu fui ajudar o professor Eliel Benites - professor kaiowa da Licenciatura Indígena Teko Arandu - e o método ele seguiu foi, justamente, o seu: de fazer uma roda ali para conversar com os professores sobre que conhecimento eles queriam valorizar naquele ano. Tinha já um consenso que eles queriam falar de água e a postura do diretor da escola era, assim: "Ah, legal. Eles podem falar de água, porque a água é um tema que conecta com sustentabilidade, que conecta com Química, com Biologia". O que eu percebi é que é mais fácil encaixar. Você resolve o problema, enquadrando o tema da água, o dono da água, nas disciplinas, do que entender, pesquisar por que os Guarani explicam que tem um tatu gigante, que cuida da mina [d'água]...

Dominique Tilkin Gallois: Ah, mesma coisa! 
Tatiane Maíra Klein: Que está muito bravo porque as pessoas estão fazendo tudo errado...

Dominique Tilkin Gallois: Isso! Ele retém ou solta água. Nossa, mesma coisa lá no Amapá! Vocês imaginam!? É muito impressionante.

Tatiane Maíra Klein: Então, fico pensando, o quanto a essa abordagem da interculturalidade, no dia a dia das escolas, parece que virou como uma chave de trabalho para os gestores, coordenadores pedagógicos, em que parece sempre possível, como você costuma dizer, "articular sistemas de conhecimento ou modos de conhecer absolutamente distintos"...

Dominique Tilkin Gallois: A maneira como - e aí [quem fala] é Marta Azevedo (2014) - "fiapos de cultura" são inseridos dentro das temáticas que são de importância para a nossa concepção de sustentabilidade, por exemplo, mostra, de fato, que os saberes acabam sendo colonizados. Para mim, toda essa onda das mudanças climáticas é típica dessa relação. Então, bem, o que eu digo? Explique qual é o conceito de mudanças climáticas, de onde ele vem. Porque ele não vem do pensamento indígena! Nem de suas experiências de vida. Faça uma explicação para dizer por que é que nos países ocidentais isso se tornou um problema, uma questão crucial... mas sem querer, de cara, importar pedacinhos dos saberes indígenas dentro do conceito, ou pior, da metodologia de descrição dessas mudanças. Na verdade, falando agora, eu acho que tem um pressuposto meu - que vou declarar aqui, penso que é importante - que, na verdade, pode ser criticado muito por antropólogos: eu acho que, diante da capacidade de absorção de pedaços de conhecimento indígena pelas nossas problemáticas científicas, os saberes locais se encontram muito fragilizados. Eles não são frágeis, senão eles não existiriam -, mas os avanços dos nossos sistemas de conhecimento sobre os sistemas de conhecimento indígenas são pesados. $\mathrm{E}$, na verdade, estão transformando os seus pressupostos epistemológicos para fazê-los caber nos nossos. Então meu método é dar espaço evitando contaminar, para que a sistematização do conhecimento seja feita antes, a partir das categorias locais. Daí, compara, confronta, debate.

Não estou dizendo que não podem saber de mudanças climáticas. Sim, mas não começando assim: "Vocês - já que são índios! - devem ter conhecimento sobre mudanças climáticas [...]" Os intelectuais indígenas, os professores, os 
pesquisadores vão fazer pontes, mas não podem fazer sem a pesquisa prévia dentro dos parâmetros de seus próprios sistemas. O conhecimento tradicional, ele existe na prática. Agora, para ser sistematizado, ou ele é sistematizado pelos antropólogos - como nós fizemos desde que a Antropologia nasceu - ou eles também passam a fazer, com uma atenção muito delicada para as categorias deles, não nossas.

A pressa de interconectar é que mata essa possibilidade. É por isso que o "inter" me incomoda. Já sabemos que não dá tempo, em uma formação rápida, no tempo de um TCC ou de um mestrado, de fazer uma coisa muito aprofundada. Então a solução é ir rapidinho e pegar uns fiapinhos e enfiar dentro do conceito do branco. Isso me leva para o ponto das traduções: a pior coisa que tem para mim é, por exemplo, pegar "mudanças climáticas" e "intercultural", forjar uma palavra na língua indígena, a partir do conceito ocidental de mudança climática. É, absolutamente, horrível. Primeiro vamos ver se esse recorte de clima faz sentido. Faz sentido ou não? Segundo, mudanças: o que é mudança? Aproximar-se do que é o conceito indígena sobre estação, como ele é pensado, por exemplo, verificar que não abrange apenas o que nos concebemos como "clima". Eu fiz uma oficina sobre isso e estação tem a ver com criação do mundo, com a teoria da pessoa humana, seu distanciamento dos criadores etc. Para os tupi, então, é maravilhoso. Aí insere o regime de chuvas, de secas... Deixá-los organizarem o material deles, antes de chamar isso de conhecimento de "mudança climática"! Eu radicalizei nisso, porque às vezes se obriga essas pessoas [a fazerem isso] em oficinas de dois dias, ou, então, em um Trabalho de Conclusão de Curso (TCC) que, geralmente, é feito na cidade, sem acesso muito aos conhecedores indígenas, sem um campo aprofundado. Os pesquisadores indígenas na universidade têm que lidar com dois sistemas de conhecimento, mas não se dá a chance a eles de ter acesso regular e intenso aos regimes de conhecimentos próprios deles. Eles são massacrados com os nossos.

Tatiane Maíra Klein: Como essa discussão sobre os saberes indígenas impacta o campo do patrimônio cultural imaterial indígena?

Dominique Tilkin Gallois: Eu fiz uma abordagem crítica da maneira como se tende a descrever o patrimônio cultural, como um campo separado, no caso dos patrimônios indígenas. Eu tendo a, justamente, definir que patrimônio cultural 
e imaterial sejam reabordados, na forma de etnografias de saberes e práticas de conhecimento local e não, apenas, buscar coisas relevantes, separadas como patrimônio. Nesses últimos 20 anos, isso se tornou uma discussão técnica, um pouco como a questão dos territórios e seus laudos. Então, há muito avanço, graças a oficinas, manuais de laudos, mas esquecendo o essencial, que é que - laudo se preenche com dados de uma etnografia rigorosa sobre organização social, chefia, territorialidade, tipo o trabalho do Levi. Sem esse conhecimento, não tem laudo possível.

Sobre o patrimônio, tem de distinguir pesquisa sobre patrimônio e divulgação do patrimônio. Hoje, o termo remete muitas vezes apenas a técnicas de divulgação. Muito porque nos governos anteriores, o que existia era muito apoio e o incentivo a uma visibilidade do patrimônio cultural, indígena ou não. Às vezes, com pouco cuidado, pouca atenção à complexidade, à interconexão entre essas coisas elevadas a patrimônio, o canto " $x$ ", o ritual " $y$ ", e a vivência do cotidiano. Eu acho que teve um auge da moda do patrimônio, porque teve também muito recurso. Quem soube aproveitar disso para fazer boas coisas, aproveitou. E agora não tem mais: neste governo, se apreende cultura de forma utilitarista, tacanha, limitada à ideia de "lazer", e quem pensa diferente é inimigo, então não tem mais nada. Mas tendeu a se autonomizar como um campo - o campo do patrimônio, a formação em patrimônio - e, de novo, eu acho isso equivocado. Qual é o conteúdo do patrimônio? Saberes e práticas. Vamos estudar Etnologia, [fazer] etnografia. O que se chama, agora, de patrimônio, eu sempre estudei - que eram os mitos, as festas, a pintura corporal, os resguardos etc. Se isto se chama patrimônio [...]

$\mathrm{O}$ assunto esteve muito em voga no momento em que o Instituto do Patrimônio Histórico e Artístico Nacional (IPHAN) se firmou, as Secretarias de Cultura se interessaram, deram visibilidade aos patrimônios indígenas. Foi muito importante, porque os indígenas começaram a aparecer. Mas agora não tem mais apoio. O que não impede que se continue fazendo pesquisas e tentando divulgar esses patrimônios, mas de uma maneira bem-feita, academicamente. Por exemplo, um dos patrimônios imateriais indígenas mais importantes, que são as línguas, ganhou até um registro próprio recentemente. Desde o tempo da Dilma [Rousseff] aquilo morreu. Então, a gente precisa cavar de novo maneiras de fazer isso aparecer: a riqueza das línguas, a diversidade das línguas, não só aquilo que agrada mais, como festas, pinturas, artes gráficas etc. 
Tatiane Maíra Klein: Durante a formação de pesquisadores wajãpi por conta do processo de patrimonialização dos desenhos kusiwa, tem pesquisas que são de alguns deles, como as pesquisas do Kasiripinã, mas também pesquisas produzidas coletivamente. Por que as pesquisas coletivas ajudam a construir descrições melhores desses sistemas de conhecimento?

Dominique Tilkin Gallois: Perfeito. É por aí. Como a gente queria que os pesquisadores indígenas fossem reconhecidos, e eles foram, no final, por um instituto federal -, então tinha que se submeter a algumas coisas, em formato de disciplinas. Uma das exigências é que eles tivessem um trabalho de pesquisa individual, mas o trabalho de pesquisa individual é só uma parte de seu investimento em pesquisa, cujos resultados só podiam ser alimentados pelas pesquisas coletivas. Então, foram várias e elas surgiam do coletivo, das oficinas com a turma toda de 20 jovens e supervisores mais velhos - os conhecedores - quando aparecia um problema a ser analisado, gerando muita discussão.

Eu me lembro, no caso dos Wajãpi, o Jawaruwa - que é o jovem que se tornou vereador e é uma liderança importante hoje -, ele foi com a Joana [Cabral], comigo [e] a Manuela [Carneiro da Cunha] para o Xingu, e assistimos a uma demonstração da chefia jê kĩsêdjê, com uma bela e longa fala de chefe. $E$ durante toda a viagem de volta ele dizia: "Ah, por que não tem chefes assim nos Wajãpi? Tem que ter um chefe central!". Então tivemos um debate sobre formas do político e surgiu uma pesquisa coletiva sobre organização social e, portanto, a organização política dos Wajãpi, quem são os chefes, por que tantos chefes etc. Só sobre esta questão, ocorreram três oficinas no ano e eles voltaram para as suas aldeias, fizeram a pesquisa, retornaram, debateram e, na terceira oficina, organizaram os resultados e evidenciaram as categorias importantes para descrever os modos do político. Graças ao projetor: antes eram cartazes escritos, agora eles redigem coletivamente com projetor na parede. E aí, pow! Qual é a palavra que vai usar? Dissensões... aí fazíamos uma oficina de tradução. Interrompia a oficina de pesquisa para dar espaço a quatro horas de tradução - tanto do wajãpi para o português, quanto do português para o wajãpi - para discutir os conceitos. Por exemplo, o conceito de gestão, gestão territorial: o que é gestão? Como é que fazemos gestão? Outra oficina que rendeu enormes discussões muito animadoras - contrapondo práticas e conceitos deles e nossos - foi a ideia de "trabalho". São essas questões que motivam uma oficina de tradução. 
Teve uma pesquisa coletiva sobre imagem, que se propunha a descrever categorias importantes da noção de pessoa, princípios vitais, morte. O objetivo era que todos eles, os 20 pesquisadores, precisavam primeiro se entender. Usariam ou não a palavra alma em português? Aí chegaram à noção de imagem, em português, que acharam mais adequada. Então, a gente fazia isso e é muito legal, porque eles vão para casa, pegam o material, trazem anotações, apresentam um por um, e daí gera uma explicação coletiva, à qual todo mundo adere. É muito animador e eu recomendo isso como uma maneira que pode até se fazer na universidade. Mas cuidado: só funciona, porque tem a volta para casa, ou seja, tem a oficina e tem o campo. É instigado a pensar o assunto, falar dele em casa, falar com pai, avó, mãe, pegar as sutilezas do uso das categorias na língua [...] E essas oficinas são feitas na língua. Algumas coisas são traduzidas, mas a primeira coisa vem falada e escrita em wajãpi e, depois, traduzida. Isso faz parte do método também. Se você vai direto para o português, tem problemas graves no tratamento das categorias, eu acho. Assim é que saiu o livrinho bilíngue l'ã: para nós não existe só imagem (WAJÃPI, 2008). O que é imagem? Imediatamente a discussão foi: "Por que a gente não gosta de foto? Vamos pensar [...]"; "O que acontece com uma foto?"; "O que ela faz?". Daí chegamos na duplicação, no perigo de você se dissociar, enfim, embarcamos em questões complexas de cosmologia. Mas eu nunca falei que a gente estava fazendo uma oficina de cosmologia. Já na universidade, você embarca nisso direto: estudo de cosmologias. Mas aí, cuidado: não vá transportar as noções da descrição etnológica de cosmologia para o modo indígena. Volte! Mande o pesquisador indígena de volta para a aldeia, para saber como se fala disso no cotidiano lá e depois traz para cá e pede para ele descrever isso em seus próprios termos. Depois, bem depois, pense na articulação possível entre essas metodologias.

Eu acompanhei algumas etapas da formação João Paulo Tukano, e a coisa mais interessante que ele me disse - uma resposta na defesa [da dissertação] dele - foi: "Teve uma certa altura que eu me dei conta que eu não sabia nada, então mudei meu projeto, porque eu não sabia. Eu não podia estudar os peixes contrapondo com os cientistas, porque eu não sabia de peixes e não dava tempo de eu aprender tudo sobre peixes". Isso é fantástico! Agora ele está no doutorado e está se dedicando a aprender. Os pesquisadores wajãpi também: "Ah, a gente [...] vai ser fácil fazer pesquisa sobre a nossa cultura!". Fácil nada! Eles se deram 
conta de que eles não sabiam. A primeira constatação é essa: "Eu não sei, eu preciso aprofundar". Se eles não fazem isso, porque supostamente eles sabem, temos um perigo muito grande. É difícil dizer isso, mas temos que dizer.

\section{RESISTÊNCIAS EPISTEMOLÓGICAS}

Tatiane Maíra Klein: Os Kaiowa e Guarani denominam os escolarizados de letrao, categoria que foi descrita pela Veronice Rossato (2020), e carrega uma crítica dos rezadores e mais velhos ao afastamento da escola e dos escolarizados desses saberes. Então é comum ouvir relatos dos acadêmicos do Teko Arandu dizendo: "Eu não conhecia nenhum rezador antes de chegar no Teko. Na minha aldeia não tem mais" ou "Eu passei a pesquisar, eu fui atrás deles, depois que eu entrei no Teko Arandu, porque eu aprendi que era importante". Estou falando de um exemplo na universidade, mas a gente sabe que isso acontece também na escola indígena...

Dominique Tilkin Gallois: É por isso que o intercultural é perigoso. Eu me lembro que - isso já faz 20 anos, não sei - o Bruce Albert vinha regularmente para o NHII e a gente tinha discussões sobre a escola. Ainda não tinha a formação de pesquisadores wajãpi, mas tinha a escola, a minha briga com a secretaria, e ele me dizia que ele preferia que os Yanomami tivessem uma escola "totalmente dos brancos", do que uma intercultural meia-boca. E "totalmente dos brancos" era como, em 1992, quando eu fui pela primeira vez visitar os Wayãpi na Guiana Francesa, os vi estudando em livros onde aprendiam sobre "nos ancêtres les gaulois" [nossos ancestrais, os gauleses], no mesmo livro que minha filha estudava no Liceu Pasteur, em São Paulo. Nada de educação diferenciada. E, de uma certa forma, era interessante, porque a escola não mexia, não atrapalhava seu sistema de práticas e saberes. E o Bruce defendia isso: que ou a escola yanomami era yanomami ou ela não era. Naquele momento, ele achava que ela deveria ser uma coisa para aprender os saberes dos brancos e ponto, sem fazer pontes malfeitas.

Eu assumo que isso me influenciou muito, porque Bruce é uma pessoa que eu admirava e que pensava muito sobre etnologia yanomami e indígena. Ao mesmo tempo, eu tinha observado a escola dos Wayãpi na Guiana Francesa e via o horror do intercultural se imiscuindo nas escolas dos Wajãpi no Brasil, pelo viés de profissionais mal preparados da Secretaria de Educação. Na verdade, acho que o "dar tempo" aos formandos indígenas para investir realmente em um 
reconhecimento do volume, diversificação, qualidade e complexidade dos saberes deles é essencial. "Antropologia Indígena" [...] Tem que saber se ela vai surgir a partir de uma revisitação dos regimes de conhecimento indígena; senão, eu não sei se será "indígena". É bem complicado.

Então não precisa fazer antropologia pós-colonial para constatar a dominação epistemológica. Eu constato isso desde que eu comecei a ir a campo, nos anos 1970 [...] então, constatando isso, vamos dar espaço, mas nos termos de quem? Quais são os modelos analíticos indígenas? O que eu quis dizer com isso é que tem que dar tempo. Se para um etnólogo branco, o tempo de aprender a língua, de se aprofundar na aproximação, de conhecer as categorias do pensamento e de análise dos indígenas é importante, para o pesquisador indígena também é. Esse tipo de coisa não está imbuído nele. Ele tem que aprender a perceber e a reconhecer. Ele tem que manter um caderno de campo: é o mesmo método.

Essa coisa da mediação [...] não tem por que ele ser um mediador imediatamente: mediar o quê, se ele não conhece os dois lados? Não é porque, eticamente, os antropólogos começaram a recusar o papel de mediador para dizer "os índios que façam", que eles [devem ser mediadores]. No campo do conhecimento antropológico, acadêmico, eles não estão mais preparados, por serem índios, do que nós. Recuso essa ideia. Porque eles primeiro têm que fazer uma boa pesquisa e, para isso, precisam fazer um bom campo. Todos os pesquisadores indígenas que eu conheci, em vários lugares, dizem: "Nossa! Eu não conhecia. Foi bom fazer essa formação em pesquisa, porque eu percebi que eu não sabia nada". A Marcela Coelho [de Souza] tratou disso nos Kĩsêdjê. Esse é o primeiro passo. Percebeu que não sabia nada? Então, vá lá e aprenda. Aí sim, os pesquisadores indígenas vão ter uma maior sensibilidade que nós em perceber as categorias e os campos semânticos em que essas categorias são atualizadas. A gente tem essa tendência de pegar uma categoria cultural e achar que ela funciona só em um campo semântico. Eles não: já sabem que essa noção é usada para conectar várias coisas, que o termo pode passar de um campo e para outro. Mas eles têm que fazer pesquisa de campo, têm que fazer anotações, têm que ser rigorosos. Não pode ir para a mediação a todo vapor. Mediar o quê? Aí eles vão ser dominados ou vão apenas fazer confronto. A mediação é perigosa quando não se tem um preparo muito sólido para comparar sistemas de conhecimento distintos. 
Levi Marques Pereira: Como você observa o crescente processo de ocupação dos cargos de professores e gestores pelos próprios indígenas nas aldeias? Isso implica necessariamente na "indigenização da escola"?

Dominique Tilkin Gallois: Eu li, recentemente, a tese do novo chefe da Coordenação [Geral] de Índios Isolados [e Recém Contatados, CGIIRC-Funai], que foi missionário da Novas Tribos. Sua tese pela Universidade Federal do Grande $A B C$ é sobre a conversão e a tradução da bíblia num povo do Javari. Sua análise menciona trabalhos meus, de Marcela [Coelho de Souza] e também de Aparecida [Vilaça], para contestá-los. Nós, obviamente, por sermos antropólogas, alertamos sobre a complexidade da transposição de um sistema de conhecimento para outro, destacando questões de tradução. Ele, ao contrário, usa a necessidade da mediação como argumento para dizer: "Os índios fazem a conexão - as antropólogas dizem que não, mas eles fazem". Claro que fazem! Mas eles fazem como? (GALLOIS, 2012). Ele não descreve os modos de análise, as operações de tradução, apenas mostra que [os indígenas] aderiram. Na verdade, não mostra como estão sendo engolidos pela linguagem do cristianismo. A mediação que eles operam não é equilibrada: a fazem purificando alguns elementos de seu pensamento, de sua cosmologia, para enfiar dentro das categorias do cristianismo e o resto é jogado fora. Então, para mim, essa coisa da mediação é um perigo, porque é através disso que se domina. Os Guarani, especialmente, falam de resistência; então temos que trabalhar em termos de resistência epistemológica. Mediação? Não. Vamos dizer tradução cuidadosa, que necessariamente é uma tradução que passa pela contraposição. A mediação tende a buscar o que é supostamente "parecido". Ora, na Antropologia desde [Claude] Lévi-Strauss, optamos por evidenciar as diferenças, ou melhor ainda, termos consciência de que comparamos incomparáveis (DETIENNE, 2000). É por isso que eu aposto primeiro na contraposição, para depois verificar como são feitas as conexões. Isso, para mim, é um caminho fundamental. Então, a leitura dessa tese de um autor evangélico, que recusa os argumentos antropológicos, porque diz que nós ficamos no campo do incomunicável, é fácil dizer. Quer dizer, o que a Aparecida e eu estamos dizendo é: "Cuidado, não é a mesma coisa". Então, o que interessa é entender como os índios fazem a mediação. Eles a fazem - não estou dizendo que eles não fazem -, mas como é que eles fazem? Tem que descrever direito os procedimentos intelectuais. Então, descrever a própria dominação epistemológica também é um bom 
caminho. Eu acho que isso poderia ser um tema de pesquisa para universitários indígenas, por exemplo: "Por que eu fiz um material que chama 'Seres vivos e inanimados"?"; "Por que eu não considerei, não salientei a concepção indígena segundo a qual tudo tem alma?"; "O que é esse negócio de 'inanimado'?"; "Por que eu absorvi essa categoria que vem dos livros escolares antiquados? Só porque existe no ensino da Biologia dos brancos?". São coisas aparentemente simples, mas se a gente não superar isso [...].

Não é porque o gestor é indígena que a escola é indigenizada; [para ser] indigenizada depende do conteúdo e da forma como funciona o ensinamento. Eu sou muito radical com relação a isso. Pensa naquele livro sobre os Waimiri, que é o chamado livro É a Funai que sabe: não é porque o cara é o chefe da Funai e indígena, que ele faz uma Funai diferente. Ao contrário, talvez esses índios que acediam a esses [cargos] se tornavam os mais colonizadores. É um perigo enorme, é um perigo enorme. Eu não sei, para mim [...] Mas, enfim, eu nunca trabalhei, gente, - tanto - nesse foco do aspecto administrativo. Vocês entendem? Para mim o negócio é [...] que escola? Para quê escola? Como se ensina? Como é feita a conexão ou não com os saberes indígenas? Por exemplo, "pedagogias escolares indígenas". Agora, que já faz pelo menos duas gerações em lugares, três - que estão na escola, podemos falar disso. Mas nos Yanomami, nos Wajãpi, na metade dos povos indígenas que não têm escola ou que têm há menos de uma geração, como é que pode ter modelos escolares pedagógicos "indígenas"? Na verdade, é isso: a gente tem que diferenciar o tempo todo. E a forma escolar é acachapante; ela é muito poderosa. Nunca vou me esquecer dos primeiros cursos de formação de professores que ofereci no Amapá, que eram para alfabetizar uma primeira turma. Uma das coisas mais difíceis, nos primeiros acompanhamentos dos alunos desses professores em formação, mesmo depois de muito tempo de formação, é que eles não conseguiam não ajudar dando a resposta. Eu ficava observando isso e a Marina Kahn, que era a formadora no começo desse processo, dizia: "Não, mas vocês não podem dar a resposta! Tem que deixar os alunos se virarem [...]"; eles falavam: "Ah, não! Isso é muito feio para nós. Ele está sofrendo. Eu vou dar a resposta!". Então tem que prestar atenção a essas formas de ensinar.

Agora, se você só pega as formas pedagógicas nossas e, porque são feitas por indígenas, diz que são indígenas [...] não. Depende! Mas a coisa mais perigosa é o 
campo das disciplinas. A gente tem que radicalizar. Criar novas disciplinas, novas articulações entre os temas. Isso já estava lá atrás nos Referenciais Curriculares da Educação Escolar Indígena (RCNEI), com muitos temas transversais, para evitar as caixinhas. Mas nunca se conseguiu, de fato, implantar isso. Então, para mim, a escola interessa pela maneira como a gente consegue que os conhecimentos indígenas, super sofisticados, sejam colocados na escola sem serem capturados. É simples assim. É isso que me interessa. Como é que a gente ajuda a evitar essa captura sistemática empobrecedora.

Levi Marques Pereira: Agora, isso também demanda um esforço coletivo dos próprios indígenas, em cada povo. Imagino que é uma coisa como um acúmulo de experiências que eles vão, aos poucos, sistematizando.

Dominique Tilkin Gallois: Sim.

Levi Marques Pereira: Não dá para pensar que um único professor vai fazer isso. Dominique Tilkin Gallois: Não. Depende justamente da política das comunidades: se elas querem diplomas para serem concorrentes na busca por salários, por trabalhos assalariados, ou se a escola é um investimento para a sustentabilidade futura da própria diferença. Alguns vão chamar isso de identidade, eu chamo de modos indígenas diferenciados. Eu esqueci de dizer lá no início que, ao longo do meu trabalho no CTI [Centro de Trabalho Indigenista] e no CEDI, eu tinha contato com gente que trabalhava com os Guarani, com os Enawenê, com os Krahô e tantos outros. Sempre trabalhei envolta em conhecimento de muitas áreas indígenas e percebia que a escola é responsável, como me dizem os professores wajãpi, por tirar os jovens das aldeias. A escola faz isso: ela leva para cidade. E uma coisa era demarcar terras e a outra é ficar com elas. Eu sempre falo: "Se vocês querem uma 'formação-certificado', eu não preciso estar aqui. Aílida com a Secretaria [de Educação]. Eu estou propondo uma 'formação-cabeça', que é para pensar. Para pensar e ajudar a manter essa terra que os avós demarcaram". Então eu sempre trabalhei nesse rumo. Agora com os Zo'é, mais ainda. Nos Wajãpi, fui a primeira a levar o ensino da Matemática; a ajudar os indígenas a aprender a dirigir; a terem carteira de motorista; a aprenderem a fazer vídeo. Mas se é para ter uma terra grande e se alimentar unicamente da compra na cidade, com o salário - e a escola serve para comprar coisas na cidade -, então, essa escola não me interessa. Os 
professores wajãpi, inclusive os mais evangélicos, me dizem: "Dominique, você avisou e é verdade: a escola está tirando o jovem da aldeia. Todo mundo quer morar na cidade". Porque com o dinheiro... não tem mercado na aldeia, então tem que gastar lá fora. E como eles não gastam mais em cerveja fazendo aquelas festas que torravam o salário de todo mundo em uma festança, em um caxiri gigante, porque eles são evangélicos, agora eles compram comida, arroz, embutidos.

Levi Marques Pereira: Você estava falando das expectativas dos velhos wajãpi em relação aos letrados novos, deles fazerem as coisas que você fazia, tipo verificar o que os brancos estão falando com respeito à terra e tudo mais. Parece que tem um certo distanciamento entre a expectativa das lideranças de comunidade - os velhos - e a formação dos novos, para onde eles são levados. Não sei o que você acha disso [...].

Dominique Tilkin Gallois: Eu posso entender e acho que em certas formações acadêmicas especialmente na Antropologia, não se prioriza esse tema da terra suficientemente. Quer dizer, parece que demarcação é uma questão mais de marco jurídico, administrativo etc. Não! Tem todo um campo de pesquisa, fantástico, sobre organização social e territorial, territorialidades. Tudo isso não é muito privilegiado. Me diz aí um curso que trata disso na Antropologia. Cadê? Não tem, né? Então, eu acho que falta, tematizar isso nos cursos de Antropologia. Na escola [indígena], os temas dos conhecimentos entraram mais, mas as questões de terra menos, porque agora você tem pesquisador estudando a "matemática indígena", "não sei quê indígena", a "história indígena", mas território não. É muito pouco e limitado. Eu vou pensar, inclusive, de bolar uma disciplina sobre isso, em algum momento.

Levi Marques Pereira: Em 2001, você disse: "Penso, como o João Pacheco [de Oliveira], que, no futuro, os antropólogos não terão que assinar laudo algum, serão os próprios grupos que vão assinar os seus próprios laudos" (SCHULER et al., 2001, p. 120). Quais contribuições podem advir das pesquisas e da atuação profissional e política de indígenas egressos de cursos de pós-graduação em Antropologia?

Dominique Tilkin Gallois: Eu falava como o João Pacheco, em uma certa altura, porque essa era uma discussão muito interessante e pesada na ABA: "Será que os indígenas podem assinar o laudo?". Na época em que essa discussão ocorria, 
não existiam antropólogos indígenas. Agora existem. Então acho que eles têm que assumir isso. Tudo dependerá muito da formação etnográfica, já que um bom laudo exige um hiperdetalhamento etnográfico na conjunção dos argumentos. Então, se - como estou criticando - as formações acadêmicas não valorizam o conhecimento aprofundado, etnográfico, da realidade das comunidades, porque está preocupada com Filosofia, pós-colonialismo, interculturalidade, todas essas coisas, vai ser difícil eles fazerem. Quem assume isso sabe que vai ter que ter um laudo: [algo] que vai desde saber o nome das plantas e das comidas e da roça, até as estações, a organização social, a organização política - tudo! Um laudo é, absolutamente, uma etnografia complexa e precisa ser preparado para escrever isso. Que eles façam, porque eles são capazes. Eles são capazes não porque são índios; eles são, porque são antropólogos indígenas. Eu espero que, mais e mais, eles o façam e não necessariamente da própria terra; poderão fazer de outras. Isso porque eles são antropólogos.

E acho que precisa incentivar isso; se eles não são incentivados, é porque é um tema que está muito enfraquecido nas formações acadêmicas. Não basta ter uma disciplina sobre laudos, que é uma coisa meio mecânica. Acho que tem que ter disciplinas sobre organização social e territorial, sobre sistemas de produção, economias indígenas. Como descrever isso? Eu me lembro que, uma vez, em uma avaliação da Coordenação de Aperfeiçoamento de Pessoal de Nível Superior (Capes), não sei quem da Universidade de Brasília (UnB) chegou lá no NHII e me provocou assim: "Por que vocês não fazem oficinas e cursos sobre laudos?"; eu falei "Porque a gente se preocupa em dar boas oficinas e bons cursos de pesquisa etnográfica. E isso é mais importante do que a política dos laudos". De novo: a política dos laudos versus o conteúdo do laudo. Eu prefiro apostar no conteúdo do laudo.

Tatiane Maíra Klein: Você escreveu há alguns anos um artigo (GALLOIS et al., 2016) destacando o papel de pesquisas de autoria indígena na Antropologia brasileira - entre eles, Tonico e Eliel Benites, que são Guarani Kaiowa. Quais são as inovações teóricas promovidas por esse movimento?

Dominique Tilkin Gallois: Justamente esses dois pesquisadores trouxeram caminhos inovadores, absolutamente brilhantes, para descrever o que os antropólogos de certa forma sempre fizeram, mas eles o fizeram de uma maneira própria. Eu 
acho que uma das maneiras mais interessantes é conectar e focalizar muito o tema da ancestralidade, que interessa muito aos autores indígenas. Questões da origem, de onde vêm as coisas, que ao mesmo tempo são um fio da memória histórica e seguem conexões entre uma coisa e outra. Então eles abrem espaço para novas maneiras de abordar tanto a transformação dos sistemas de conhecimento, quanto transformações na organização social. Eles vão seguindo essas narrativas de origem e dão um jeito de pesquisar como eles mesmos aprenderam, refletindo sobre a própria experiência. Isso é muito legal e só eles podem fazer isso, porque eles estão falando de conexões entre saberes que eles vivenciaram.

Teve um certo momento na antropologia chamada pós-moderna, em que se dava espaço para o antropólogo dizer como ele chegou lá - quando ele não foi simplesmente jogado naquela praia, mas -, como é que ele foi lá [...] E aí as teses e trabalhos começavam a dar um espaço excessivo ao antropólogo falando de si, em vez de falar dos outros, e o "eu etnográfico" muito presente. Eu não gostava, porque eu acho que tem que dar o contexto da relação que você tem, pronto e acabou; agora vamos ao tema. No caso dos indígenas é totalmente diferente, porque como eles são parte dessa comunidade, é essencial que se situem no campo de relações e aprendizados que tiveram, dentro e fora da terra indígena. Isso traz uma luz muito clara sobre os conceitos que eles estão operando. Acho que eles vão trazer inovações teóricas muito legais: vão renovar a ideia de transmissão, vão renovar a ideia de ancestralidade, a maneira como uma certa antropologia estrutural não gostava de pesquisar a origem - e eles estão trazendo de volta toda a questão da origem. Eles têm coisas muito, muito interessantes.

Enfim, cabe dizer que tem várias antropologias se fazendo em um departamento, então, que dirá, no Brasil, e dependendo de onde eles caem, os pesquisadores indígenas vão ser formados com vieses diferentes. Tem uns que vão estudar Darcy Ribeiro e a identidade étnica. Fazer o quê? Não é a formação que eu quero dar, mas a capacidade deles - eu tenho certeza - de fazer bons trabalhos inovadores em Antropologia, depende deles fazerem uma boa etnografia, também tenho certeza disso. Eu não acho que eles vão ser capazes de inovar, se continuam se preocupando com problemáticas abordadas em termos de aculturação ou de identidade étnica. Isso já foi. Teria que tirar isso da pauta de formação deles. Estou reivindicando mais etnologia na formação deles, porque é ali que eles vão inovar. Eu acho, enfim; espero. 


\section{REFERÊNCIAS}

AZEVEDO, Marta Maria. Apresentação sobre direitos dos povos indígenas em mesa redonda: índio é nós. Casa do Povo, São Paulo, 2014. (Seminário)

BARBOSA, Gabriel Coutinho. Os Aparai e Wayana e suas redes de intercâmbio. Tese (Doutorado em Antropologia Social) - Universidade de São Paulo, São Paulo, SP, 2007.

BARBOSA, Catarina. "R\$600 da morte": deslocamento para receber auxílio expõe indígenas à covid-19. Brasil de Fato, Belém, 2020. Disponível em https://www.brasildefato.com.

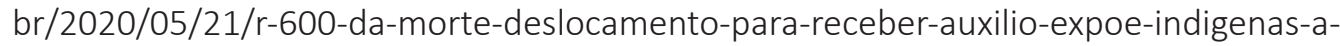
covid-19. Acesso em: 29 set. 2020.

DETIENNE, Marcel. Comparer l'incomparable. Paris: Seuil, 2000.

DIAS JUNIOR, Carlos Machado. Entrelinhas de uma rede: entre linhas Waiwai. 2005. Tese (Doutorado em Antropologia Social) - Universidade de São Paulo, São Paulo, 2005.

GALLOIS, Dominique Tilkin. Saberes indígenas na escola: o que se ganha, o que se perde, o que se transforma. In: SERAGUZA, Lauriene; PEREIRA, Levi Marques. Etnologia guarani: diálogos e contribuições. Dourados: UFGD, 2021. [No prelo].

GALLOIS, Dominique Tilkin; TESTA, Adriana Queiroz; VENTURA, Augusto; BRAGA, Leonardo Viana. Ethnologie brésilienne: les voies d'une anthropologie indigène. Brésil(s), Paris, n. 9, 2016. 18 p. doi: https://doi.org/10.4000/bresils.1897.

GALLOIS, Dominique Tilkin. Traduções e aproximações indígenas à mensagem cristã. Cadernos de Tradução, Florianópolis, v. 2, n. 30, p. 63-82, 2012.

GALLOIS, Dominique Tilkin. Redes de relações nas Guianas. São Paulo: Editora Humanitas, 2005.

SCHULER, Evelyn; FERRARI, Florencia; SZTUTMAN, Renato; MACEDO, Valéria. Essa incansável tradução. [Entrevista concedida por Dominique Tilkin Gallois]. Sexta Feira, [s.l.], n. 6, 2001.

GRUPIONI, Luís Donisete Benzi. Olhar longe, porque o futuro é longe: cultura, escola e professores indígenas no Brasil. Tese (Doutorado em Antropologia Social) - Universidade de São Paulo, São Paulo, SP, 2008.

LIMA, Tânia Stolze. O dois e seu múltiplo: reflexões sobre o perspectivismo em uma cosmologia tupi. Mana, Rio de Janeiro, v. 2, n. 2, p. 21-47, 1996. 
ROSSATO, Veronice Lovato. Será o letrado ainda um dos nossos? Os resultados da escolarização entre os Kaiowá e Guarani em Mato Grosso do Sul. Veranópolis: Diálogo Freiriano, 2020.

SAHLINS, Marshall. Cosmologias do capitalismo: o setor transpacífico do sistema mundial. In: SAHLINS, Marshall. Cultura na prática. Rio de Janeiro: UFRJ, 2004 [1988]. p. 445-502.

WAJÃPI. I'ã: para nós não existe só “imagem”. Macapá: lepé/Apina, 2008.

VIVEIROS DE CASTRO, Eduardo. Os pronomes cosmológicos e o perspectivismo ameríndio. Mana, Rio de Janeiro, v. 2, n. 2, p. 115-44, 1996.

\section{Sobre os autores:}

Tatiane Maíra Klein: Doutoranda em Antropologia Social pela Universidade de São Paulo (USP). Mestre em Antropologia Social pela USP. Graduada em Comunicação Social pela USP. E-mail: tatimaklein@gmail.com. Orcid: https://orcid.org/0000-0001-6384-0144

Levi Marques Pereira: Doutor em Antropologia Social pela Universidade de São Paulo (USP). Mestre em Antropologia Social pela Universidade Estadual de Campinas (UNICAMP). Graduado em Ciências Sociais pela Pontifícia Universidade Católica de Campinas (PUC-Campinas). Docente na Universidade Federal da Grande Dourados (UFGD). E-mail: levipereira@ufgd.edu.br. Orcid: https://orcid.org/0000-0002-8513-2613

Recebido em: 12/11/2020

Aprovado para publicação: 16/12/2020 